\title{
The intraoral permeability measurement as a screening for artifact formation by orthodontic products in MRI
}

\author{
Felix H. Blankenstein ${ }^{1}$. Ulrike Kielburg' • Ludwig Melerowitz' • Daniel Stelmaszczyk ${ }^{2}$ \\ Received: 2 December 2020 / Accepted: 22 September 2021 \\ (c) The Author(s) 2021
}

\begin{abstract}
Aim Metal dental products lack precautionary statements regarding MR compatibility due to an exemption in the labelling obligation. Hence, it is difficult for radiologists to decide whether to remove fixed metal objects in patients prior to MRI. A solution could be the direct determination of the magnetic permeability $\left(\mu_{\mathrm{r}}\right)$ as a decisive material-related predictor of artifact formation and other interactions. Thus, the applicability of an industrially used measurement device as a screening instrument and the relevance of the manufacturer's application restrictions in vitro and in vivo were tested.

Methods Precision and trueness were tested using self-made test objects with different dimensions and different permeability. To clarify whether the measurement results are affected by the remanence $\left(\mathrm{B}_{\mathrm{R}}\right)$ induced in the objects, 28 brackets of different materials were exposed to a weak and a strong external magnetic field and the magnetic flux density before and after these exposures was compared. The clinical test was performed on a volunteer with an orthodontic appliance experimentally composed of brackets with different levels of magnetic permeability $\left(\mu_{\mathrm{r}}\right)$. Validity and intra- and interrater reliability were calculated using two rater groups consisting of four dentists and four medical-technical radiology assistants (MTRA), respectively.

Results With coefficients of variation below $0.14 \%$, precision was excellent regardless of object surface and size. Trueness was high on objects with $\mu_{\mathrm{r}} \leq 1.002$, and decreased with increasing $\mu_{\mathrm{r}}$, for which size-dependent correction factors were calculated. Intra- and interrater reliability and validity were excellent and independent of professional intraoral manipulation experience.

Conclusions The permeability measurement allows for a valid and reliable determination of the magnetizability of intraoral metal objects. When used as a screening tool to detect nonartifact-causing objects, no correction factor needs to be calculated. For the first time, it offers radiologists a decision support for the selective removal of only the highly permeable components of the multiband apparatus.
\end{abstract}

Keywords Magnetic resonance imaging $\cdot$ Brackets $\cdot$ Validity $\cdot$ Reliability $\cdot$ Artifact-screening

Dr. med. Felix H. Blankenstein

felix.blankenstein@charite.de

1 Department of Prosthodontics, Geriatric Dentistry and Craniomandibular Disorders, Charité-Universitätsmedizin Berlin, Corporate Member of Freie Universität Berlin, Humboldt-Universität zu Berlin and Berlin Institute of Health, Aßmannshauser Str. 4-6, 14197 Berlin, Germany

2 Branch office Stendal, Clinic for Radio oncology, Johanniter Ltd., Wendstraße 31, 39576 Stendal, Germany 


\section{Die intraorale Permeabilitätsmessung als Screening der Artefaktbildung durch orthodontische Produkte in der MRT}

\section{Zusammenfassung}

Ziel Bei zahnmedizinischen Produkten aus Metall fehlen aufgrund einer Ausnahmeregelung in der Kennzeichnungspflicht Vorsichtshinweise zur MR(Magnetresonanz)-Kompatibilität. Daher ist es für Radiologen schwierig zu entscheiden, ob festsitzende Metallobjekte bei Patienten vor der MRT (Magnetresonanztomografie) entfernt werden sollen. Eine mögliche Lösung könnte die direkte Bestimmung der magnetischen Permeabilität $\left(\mu_{\mathrm{r}}\right)$ als ein entscheidender materialbedingter Prädiktor für Artefaktbildung und andere Wechselwirkungen sein. Daher prüften wir die Eignung eines industriell genutzten Messgerätes als Screeninginstrument und untersuchten die Relevanz der vom Hersteller angegebenen Einsatzbeschränkungen in vitro und in vivo.

Methoden Zur Prüfung von Präzision und Richtigkeit dienten selbstgefertigte Prüfkörper mit unterschiedlichen Dimensionen und unterschiedlicher Permeabilität. Zur Klärung, ob eine in den Objekten induzierte Remanenz $\left(\mathrm{B}_{\mathrm{R}}\right)$ die Messergebnisse beeinträchtigt, wurden 28 Brackets aus unterschiedlichen Materialien einem schwachen und einem starken Fremdmagnetfeld ausgesetzt und die magnetische Flussdichte vor und nach diesen Expositionen verglichen. Die klinische Prüfung fand an einem Probanden mit einer experimentell aus unterschiedlich permeablen Brackets zusammengesetzten orthodontischen Apparatur statt. Für die Berechnung von Validität sowie Intra- und Interrater-Reliabilität wurden 2 Untersuchergruppen aus je 4 Zahnärzten und medizinisch-technischen Radiologieassistenten (MTRA) gebildet.

Ergebnisse Mit Variationskoeffizienten unter $0,14 \%$ war die Präzision unabhängig von Objektoberfläche und Größe exzellent. Die Richtigkeit war auf Objekten mit $\mu \mathrm{r} \leq 1,002$ hoch. Sie verringerte sich mit steigendem $\mu_{\mathrm{r}}$, wofür größenabhängige Korrekturfaktoren berechnet wurden. Die Intra- und Interrater-Reliabilität sowie Validität waren exzellent und unabhängig von beruflicher Erfahrung mit intraoraler Manipulation.

Schlussfolgerungen Die Permeabilitätsmessung ermöglicht eine valide und reliable Bestimmung der Magnetisierbarkeit intraoraler Metallobjekte. Wenn sie als Screeninginstrument zur Erkennung nicht Artefakt verursachender Objekte eingesetzt wird, bedarf es keines Korrekturfaktors. Sie bietet dem Radiologen auch erstmals eine Entscheidungshilfe für die selektive Entfernung einzelner hochpermeabler Komponenten der Multibandapparatur.

Schlüsselwörter Magnetresonanztomografie $\cdot$ Brackets $\cdot$ Validität $\cdot$ Reliabilität $\cdot$ Artefakt-Screening

\section{Introduction}

Patients with medical implants can only be legally examined in an MRI if these products can be unmistakably identified and are labeled by the manufacturer as "MR safe" or "MR conditional" including the conditions to be met [1]. According to the EU Medical Devices Regulation 2017/745, information on the behavior of a medical device in a magnetic field must be provided in the instructions for use [24]. However, chapter II, article 18 (3) exempts some products used in dentistry and oral surgery from this obligation, including fixed orthodontic appliances. Radiologists thus lack the simplest source of information for assessing the risks emanated by these metal objects in MRI. At least, there are more reliable data on the potential heating and force effects: brackets heat up by less than $1^{\circ} \mathrm{C}$, while wires were found to increase by a maximum of $3{ }^{\circ} \mathrm{C}[11,20,22$, 26]. Forces acting on correctly anchored brackets and wires are also harmless, which is about a factor of 1000 below the force required for debonding [13].

The data on the formation of susceptibility artifacts is much less reliable. This is because a systematic error runs through the relevant literature: often only individual prod- ucts are examined as representative of the entire product range. Therefore the authors generalize that steel products should be generally removed for artifact-free diagnostics $[2,5,8,17,18,21,25]$. This coincides with the everyday experience at the MRI, where brackets made of magnetizable steel grades can erase the entire visceral cranium or even render the entire imaging system unusable, depending on the artifact susceptibility of the MRI sequence. However, this ignores the wide range of steels that can be used for orthodontic products, including the stable nonmagnetic steel grades that can remain in situ during MR imaging. A solution to this lack of information could be a direct intraoral test of magnetizability expressed as the relative magnetic permeability $\mu_{\mathrm{r}}$. This dimensionless parameter is defined as the ratio $\mu / \mu_{0}$ (permeability of a specific medium/ vacuum permeability) and describes the magnetizability of a material in response to an external magnetic field.

The relative magnetic permeability $\left(\mu_{\mathrm{r}}\right)$ is the crucial material-related predictor for the occurrence of susceptibility artifacts [3]. From the commercially available measuring instruments, we selected an easy-to-use device, the "Ferromaster" (Stefan Mayer Instruments, Dinslaken, Germany). Its measuring range extends to values between 1.001 and 


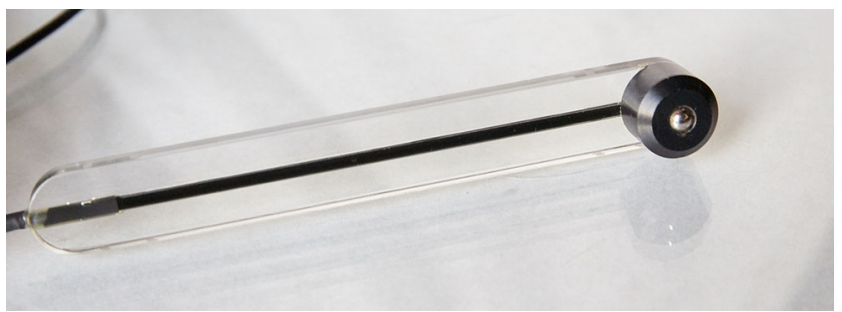

Fig. 1 The modified probe head

Abb. 1 Der modifizierte Tastkopf

1.999 with a resolution of 0.001 . In the probe head, a permanent magnet generates a constant field of $35 \mathrm{kA} / \mathrm{m}$. Two field probes measure the field inhomogeneity generated during placement, from which $\mu_{\mathrm{r}}$ of the object is calculated. The measuring deviation is given with $\mathrm{f}=\left(\mu_{\mathrm{r}}-1\right) \times 5 \%$ [23]. The device was originally designed for quality control of nonmagnetizable stainless steels, e.g. in the vicinity of electron microscopes and MRI devices.

In a previous study with orthodontic products in a chambered phantom, we used the Ferromaster and found a correlation between $\mu_{\mathrm{r}}$ and the artifact extension for each a typical spin echo and gradient echo sequence [4]. However, such studies are still not available for the many other sequences and their modifications. In the present study, we now wanted to investigate the extent to which direct permeability measurement can be used to make a valid and reliable decision about leaving or removing small medical metal objects before MRI.

In order to improve handling and hygiene during intraoral use, the manufacturer modified the probe head of the device purchased for this study so that it differed from the series production (Fig. 1).

However, the manufacturer specifies three application restrictions to ensure the measuring accuracy:

- The objects should have a flat surface.

- The objects should have a minimum size of $d=20 \mathrm{~mm}$ and $\mathrm{h}=5 \mathrm{~mm}$.

- Objects that have already been exposed to a magnetic field should be demagnetized before permeability measurement due to the induced remanence $\left(B_{R}\right)[23]$.
Yet, these limitations affect the whole range of metallic brackets and wires: they are all significantly smaller than the minimum size (further described as "undersized"), their surfaces facing the oral cavity are not flat, and it is usually unknown whether they have already been exposed to an external magnetic field.

The present study was intended to firstly clarify the relevance of these limitations for clinical use on orthodontic and similar metal objects by determining the precision and trueness of the measurement method on regular and undersized objects under laboratory conditions. Subsequently, the intra- and interrater reliability and the validity of the measurement was determined under clinical conditions. The influence of additionally ligated arch wires on the one hand and the dental professional experience of the raters on the other hand was investigated.

Finally, it was the aim to clarify whether the method is suitable for a screening instrument for the magnetizability of intraoral metal objects.

\section{Materials and methods}

\section{In vitro precision}

Three objects of different sizes were used for this purpose, including one with an uneven surface (Table 1). After initial zeroing of the device, $\mu_{\mathrm{r}}$ of each of these objects were measured 20 times. We used the coefficient of variation $(\mathrm{CV})$, which is calculated as the quotient of the standard deviation and mean value and is expressed as a percentage. Values below $10 \%$ are considered as high precision, whereas a $\mathrm{CV}$ greater than $30 \%$ indicates an unacceptably scattering of the method [19].

\section{In vitro trueness (accuracy of the mean)}

By mixing the cold-curing PMMA plastic Technovit 4004 (Kulzer Ltd., Hanau, Germany) with varying amounts of a carbonyl iron powder, a total of 26 masses were produced. Depending on the iron content, their $\mu_{\mathrm{r}}$ value was between 1.00 and 1.96. Four cylinders were cast from each of these masses: One reference body each with diameter $(d)=45 \mathrm{~mm}$

Table 1 Determination of the precision of the Ferromaster measurement Tab. 1 Bestimmung der Präzision der Ferromaster-Messung

\begin{tabular}{lll}
\hline Objects & 20 measurements $\overline{\mathrm{x}}$ of $\mu_{\mathrm{r}} \pm \mathrm{SD}$ & $\mathrm{CV}$ (in \%) \\
\hline $\begin{array}{l}\text { Cylindrical calibration body of the Ferromaster with } \mu_{\mathrm{r}}=1.36 \\
\mathrm{~h}=9 \mathrm{~mm} / \mathrm{d}=49 \mathrm{~mm} \text { - plane surface }\end{array}$ & $1.360 \pm 0.00136$ & 0.10 \\
$\begin{array}{l}\text { Cylindrical undersized test specimen } \\
\mathrm{h}=3.6 \mathrm{~mm} / \mathrm{d}=7.8 \mathrm{~mm} \text { - plane surface }\end{array}$ & $1.274 \pm 0.00179$ & 0.14 \\
$\begin{array}{l}\text { Steel bracket Empower self-ligating } 11 \text { (American Orthodontics) } \\
\mathrm{h}=2.2 \mathrm{~mm} / \mathrm{l}=3.4 \mathrm{~mm} \text {-rugged surface }\end{array}$ & $1.280 \pm 0.00146$ & 0.11 \\
\hline
\end{tabular}

$S D$ standard deviation, $C V$ coefficient of variation, $h$ height, $d$ depth 


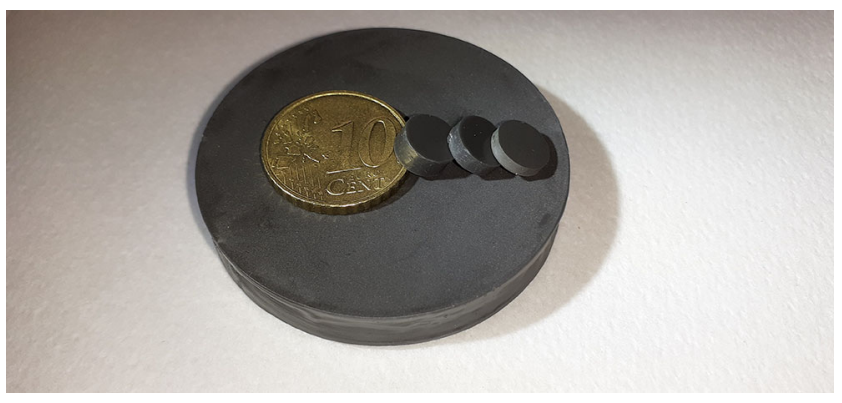

Fig. 2 One of the 26 groups of specimens for determination of in vitro trueness. They each consisted of one sufficiently large reference body and three significantly undersized test specimens. The coin illustrates the size ratios. The physical data are shown in Table 3

Abb. 2 Eine der 26-Proben-Gruppen zur Bestimmung der In-vitroRichtigkeit. Sie bestanden jeweils aus einem ausreichend großen Referenzkörper und 3 deutlich unterdimensionierten Probekörpern. Die Münze veranschaulicht die Größenverhältnisse. Die physikalischen Daten sind in Tab. 3 aufgeführt

and height $(\mathrm{h})=8 \mathrm{~mm}$, which exceeds the required minimum size, and three undersized test specimens each with $\mathrm{d}=7.8 \mathrm{~mm}$ and the different heights of $1.6,2.6$ and $3.6 \mathrm{~mm}$ (Fig. 2). On a total of 78 test specimens we then measured $\mu_{\mathrm{r}}$, compared it with the values of the 26 associated reference bodies and evaluated the differences mathematically. The set values of the reference bodies were compared with the actual values of the test specimens. A correction factor was determined based on the gradient of the compensation line resulting from the distribution of the points.

\section{Influence of remanence $\left(B_{R}\right)$}

Two specimens each of 14 commercially available metal brackets made of different alloys (Table 2), which according to the manufacturer's specifications had not yet been exposed to a magnetic field, served as test specimens. To check whether a remanent magnetization was already present, the existing flux density (measurement A) was determined initially. The device Teslameter FM 220 (Projekt Elektronik Mess- und Regelungstechnik GmbH, Berlin, Germany) was used for this purpose. Its measuring deviation is stated as $\pm 0.5 \%+2$ digits at $25^{\circ} \mathrm{C}$. As a second step, the initial value of $\mu_{\mathrm{r}}$ was determined (measurement $\mathrm{D}$ ). This step also served as the first exposition of the brackets in an external magnetic field, the approx. $0.04 \mathrm{~T}$ strong field of the Ferromaster probe. The subsequent measurement of the flux density (measurement B) now showed whether a remanent field was induced in the brackets and at what level.

The second exposure was performed in the main field of a $1.5 \mathrm{~T}$ MRI Aera (Siemens AG, Healthcare Sector, Erlangen, Germany). Its point of maximum field strength of $1.9 \mathrm{~T}$ is located in the tunnel behind the upper gantry opening. Brackets were positioned for about six seconds in this "worst case" zone. Then the final determination of $B_{R}$ (measurement $\mathrm{C}$ ) and $\mu_{\mathrm{r}}$ (measurement $\mathrm{E}$ ) was performed.

\section{Validity and inter-/intrarater reliability}

Two deep-drawn bite splints made of polymethyl methacrylate (PMMA) with vestibularly attached brackets in the 1st, 2nd and 3rd quadrant were made for an adult test person with naturally healthy teeth. The products selected for this purpose were not equivalent to a clinically applicable device, but they were assembled exclusively on the basis of their different $\mu_{\mathrm{r}}$ values between 1.001 and 1.444 (measured under laboratory conditions, uncorrected). In the 1st quadrant a 16-round steel arch made of the metastable austenitic steel 1.4310 was ligated. In the 2 nd quadrant a 17/25 titanium-molybdenum (TMA) arch was used, the 3rd quadrant remained without arch. With 21 brackets and two wires a total of 23 measuring points were obtained. The R-package ICC.sample.size was used to calculate the required number of examiners. We assumed an ICC of 0.5 and for the null hypothesis the value 0 with $n=23$ and $\alpha=0.05$ (two-sided). This resulted in a power of over $90 \%$ for four examiners. Two groups of examiners were formed, who differed in their professional experience with manipulations in the oral cavity: four dentists employed at a university dental clinic and four medical-technical radiology assistants (MTRA) from a university radiological institute, each with several years of professional experience.

Initially, a $15 \mathrm{~min}$ briefing was given on the aim and procedure of the study and on the handling of the measuring device. During the measurements, the test person sat on a simple chair without headrest. No additional instruments were used. At the beginning and at the end of the measurement in each quadrant the device was zeroed. As soon as the examiner had placed the probe head stably on the respective object, he announced the display value. At intervals of 3 weeks, two repeat measurements were carried out under identical conditions. The study was single blinded: Only the study director, who was not involved in recording the measurement results, knew the magnetic properties of the objects used.

Statistical evaluation was performed using SPSS 23.0 (IBM, Armonk, NY, USA). The Cronbach's alpha $(\alpha)$ method was used to quantify the reliability, with values $>0.9$ indicating excellent agreement [6]. After evaluation of a normal distribution of all measurement series, the single Pearson's correlation coefficient $r$ was applied to compare the intraoral measurement values with the laboratory values (validity). Values between 0.8 and 1 represent a strong to perfect positive correlation [9]. The reliability of the measurement series of the individual examiners was tested by comparing the mean values with the correspond- 


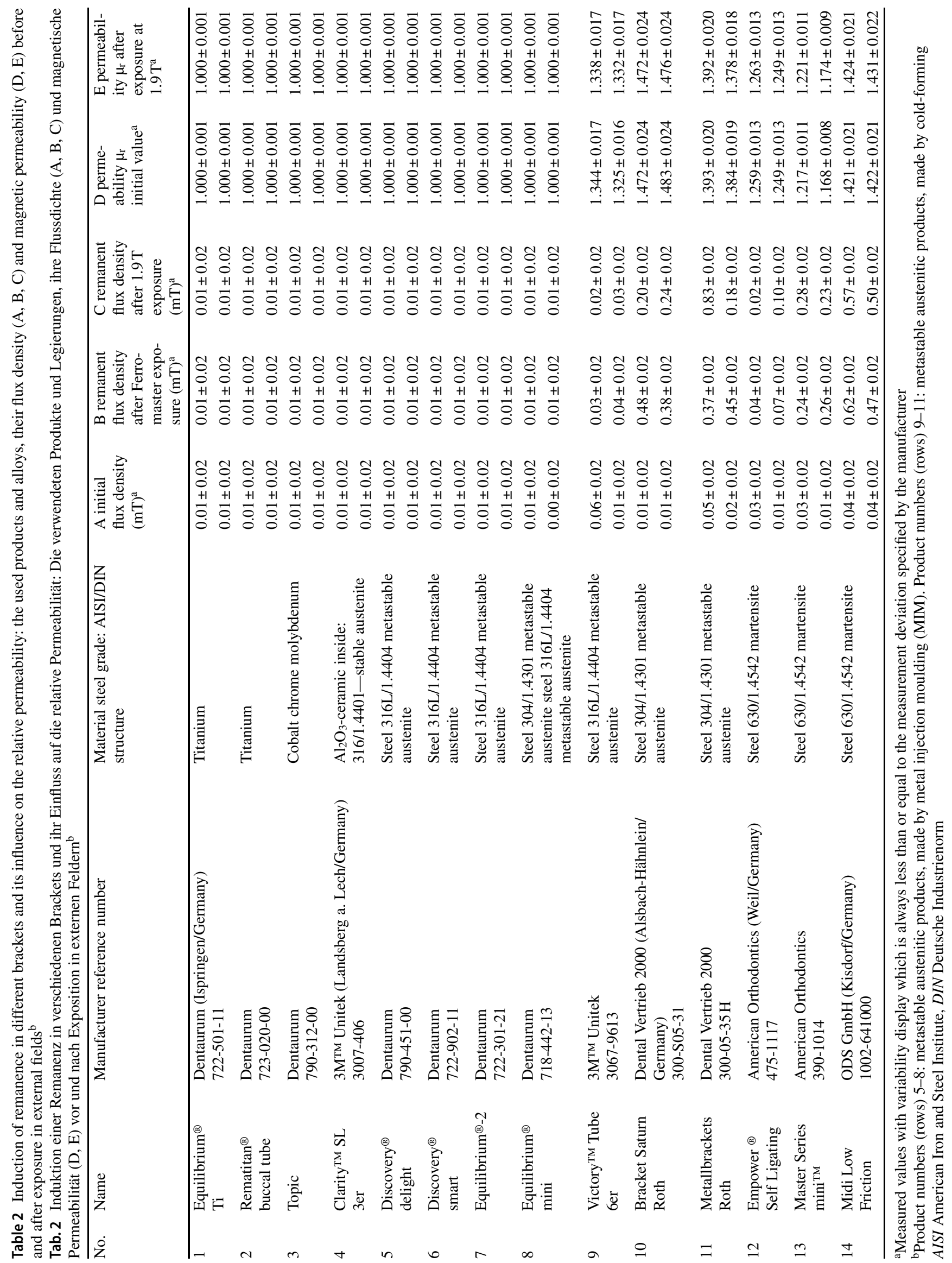


Table 3 Relative permeability of the correctly dimensioned reference bodies and three corresponding undersized test specimens each made of 26 different PMMA-iron mixtures

Tab. 3 Relative Permeabilität der korrekt dimensionierten Referenzkörper und dreier zugehöriger unterdimensionierter Probekörper aus jeweils 26 verschiedenen PMMA-Eisen-Mischungen

\begin{tabular}{|c|c|c|c|c|}
\hline \multirow{2}{*}{$\begin{array}{l}\text { PMMA-iron } \\
\text { mixture } \\
\text { No. }\end{array}$} & \multirow{2}{*}{$\begin{array}{l}\mu_{r} \text { of the } \\
\text { reference } \\
\text { body "set } \\
\text { values" }\end{array}$} & \multicolumn{3}{|c|}{$\begin{array}{l}\mu_{r} \text { of the three undersized test speci- } \\
\text { mens "actual value" with }\end{array}$} \\
\hline & & $\mathrm{h}=3.6 \mathrm{~mm}$ & $\mathrm{~h}=2.6 \mathrm{~mm}$ & $\mathrm{~h}=1.6 \mathrm{~mm}$ \\
\hline 1 & 1.000 & 1.000 & 1.000 & 1.000 \\
\hline 2 & 1.013 & 1.006 & 1.005 & 1.004 \\
\hline 3 & 1.028 & 1.014 & 1.012 & 1.010 \\
\hline 4 & 1.040 & 1.018 & 1.017 & 1.013 \\
\hline 5 & 1.062 & 1.028 & 1.025 & 1.021 \\
\hline 6 & 1.089 & 1.039 & 1.038 & 1.032 \\
\hline 7 & 1.101 & 1.045 & 1.040 & 1.034 \\
\hline 8 & 1.132 & 1.057 & 1.052 & 1.042 \\
\hline 9 & 1.159 & 1.071 & 1.065 & 1.052 \\
\hline 10 & 1.173 & 1.077 & 1.071 & 1.057 \\
\hline 11 & 1.191 & 1.089 & 1.079 & 1.063 \\
\hline 12 & 1.205 & 1.090 & 1.084 & 1.067 \\
\hline 13 & 1.225 & 1.098 & 1.093 & 1.074 \\
\hline 14 & 1.242 & 1.105 & 1.096 & 1.080 \\
\hline 15 & 1.271 & 1.117 & 1.108 & 1.085 \\
\hline 16 & 1.301 & 1.131 & 1.121 & 1.097 \\
\hline 17 & 1.346 & 1.149 & 1.137 & 1.110 \\
\hline 18 & 1.375 & 1.156 & 1.144 & 1.115 \\
\hline 19 & 1.425 & 1.182 & 1.163 & 1.128 \\
\hline 20 & 1.495 & 1.200 & 1.184 & 1.147 \\
\hline 21 & 1.540 & 1.221 & 1.193 & 1.157 \\
\hline 22 & 1.588 & 1.235 & 1.216 & 1.164 \\
\hline 23 & 1.636 & 1.255 & 1.224 & 1.177 \\
\hline 24 & 1.725 & 1.289 & 1.258 & 1.196 \\
\hline 25 & 1.784 & 1.292 & 1.276 & 1.210 \\
\hline 26 & 1.962 & 1.343 & 1.315 & 1.254 \\
\hline
\end{tabular}

PMMA polymethyl methacrylate, $h$ height

ing laboratory values. The 5\% level was defined as the significance threshold.

\section{Results}

\section{In vitro precision}

The very low values of the coefficients of variation showed a very high precision both on the calibration body and on the significantly smaller and additionally nonplanar test specimen. Taking into account the device measurement deviation, there was no difference between the results for the objects (Table 1).

\section{In vitro trueness (accuracy of mean)}

Table 3 shows the increasing $\mu_{\mathrm{r}}$ values of the 26 reference bodies from 1.000 to 1.962 (set values) and the three corresponding test specimens of different heights (here called actual values). Even with the cylinders made from mass two, there was a small difference between the set values and the smaller actual values. This difference increased both with thinner test pieces and with increasing permeability number of the 26 masses. Fig. 3 compares the three actual value curves of the test specimens with the set value curve of the reference bodies. A compensation line $y=m \times x+b$ was generated, which necessarily runs through the y-axis segment $b=1$. Its gradient shows the percentage of the actual values from the corresponding set value. The reciprocal value of this gradient thus corresponds to the respective correction factor $\mathrm{K}$ :

- at $\mathrm{h}=3.6 \mathrm{~mm}: 39.4 \% ; \mathrm{K}=2.54$

- at $\mathrm{h}=2.6 \mathrm{~mm}: 35.9 \% ; \mathrm{K}=2.78$

- at $\mathrm{h}=1.6 \mathrm{~mm}: 28.3 \% ; \mathrm{K}=3.54$

The respective correction factor $(\mathrm{K})$ for the selected test specimen height must be entered into the resulting formula for the calculation of the correct permeability number: $\mu_{\mathrm{r} \text { corrected }}=1+\left(\mu_{\mathrm{r} \text { actual }}-1\right) \times \mathrm{K}$. This showed that, taking into account the measuring deviation of the Ferromaster, the observed differences each have a constant factor. As shown in Fig. 4, the corrected actual values of the two exemplary selected test specimen heights of 1.6 and $3.6 \mathrm{~mm}$ approximately lie on the nominal straight line, indicating that the correction formulae are accurate. The plot of the set and actual straight lines shows that no correction is necessary for a measured permeability number $\mu_{\mathrm{r} \text { actual }} \leq 1.002$.

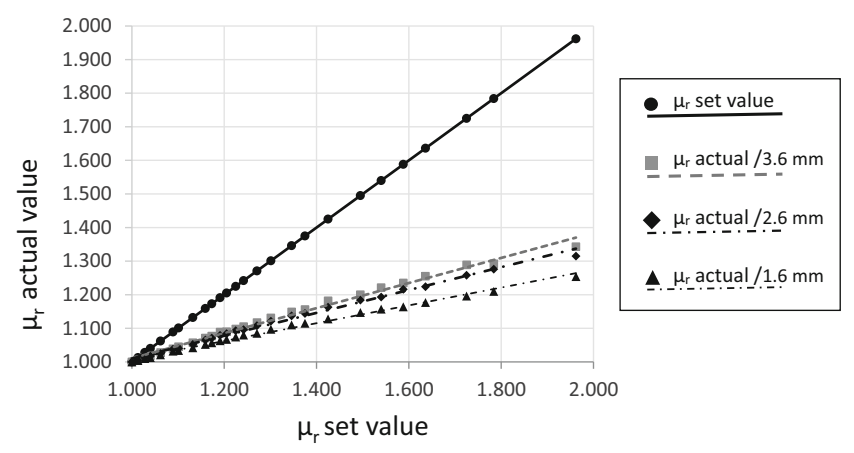

Fig. 3 Comparison of set values and actual values of the relative permeability measured on the 26 reference bodies and the respective three undersized test specimens

Abb. 3 Vergleich von Soll- und Istwerten der relativen Permeabilität, gemessen an den 26 Referenzkörpern und den jeweils 3 unterdimensionierten Prüfkörpern 
Fig. 4 Corrected actual values with $\mu_{\mathrm{r}}$ corr $=1+\left(\mu_{\mathrm{r}}\right.$ actual $-1) \times K$. a Test specimens height $3.6 \mathrm{~mm} / \mathrm{K}=2.54$, b Test specimens height $1.6 \mathrm{~mm} / \mathrm{K}=3.54$ Abb. 4 Korrigierte Ist-Werte mit $\mu_{\mathrm{r}}$ corr $=1+\left(\mu_{\mathrm{r}}\right.$ actual $-1) \times K$. a Prüfkörperhöhe $3,6 \mathrm{~mm} / \mathrm{K}=2,54$, b Prüfkörperhöhe $1,6 \mathrm{~mm} / \mathrm{K}=3,54$ a

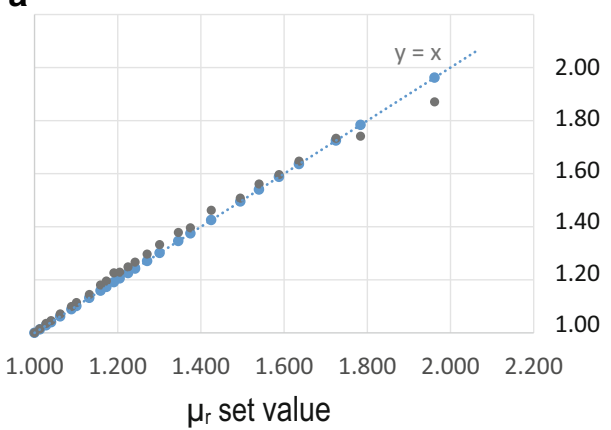

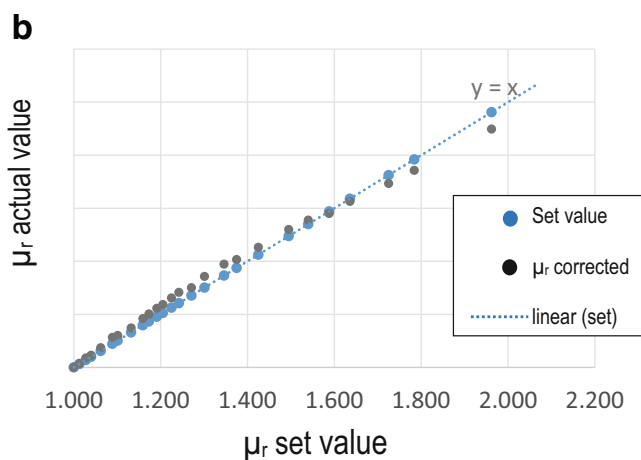

\section{Influence of remanence}

With regard to magnetizability, the 14 different bracket types in Table 2 can be divided into two groups: The brackets listed under numbers 1-8 consist of various materials: titanium, CoCrMo alloy, ceramic or metastable austenitic steels. They can all be identified as paramagnetic with $\mu_{\mathrm{r}}=1.000$ by means of the measurement $\mathrm{D}$. They do not amplify an externally applied magnetic field and are considered nonmagnetic by definition. Accordingly, no residual magnetic field could be detected in these brackets after exposure to weak or strong external fields (measurement B and C). All measurements up to $0.01 \mathrm{mT}$ lay within the measuring deviation. The bracket numbers 9-14 are made from metastable austenitic or martensitic steels. Measurement D with $\mu_{\mathrm{r}} \gg>1$ proved them to be ferromagnetic. A weak remanent field of max. $0.6 \mathrm{mT}$ was induced by contact with the probe (measurement $\mathrm{B}$ ), which did not further increase after the second exposure at $1.9 \mathrm{~T}$ (measurement $\mathrm{C}$ ). $\mu_{\mathrm{r}}$ did not change after MRI exposure in all 14 bracket types (measurement E) compared to the initial value (measurement D). Any differences that occurred lay within the measuring deviation. Thus, the induction of a remanent field did not affect the results of the permeability measurement.

\section{Reliability and validity}

First, the interrater reliability within the two groups was calculated across all 23 measuring points (Table 4). The group of the dentists showed excellent agreement in their measurements indicated by a Cronbach's alpha $(\alpha)$ of 0.992 . The correlations between the individual dentists lay between 0.975 and 0.960 . There were no significant differences between the four group members. In the group of the MTRAs, a slightly lower but also excellent agreement was achieved with $\alpha=0.979$. With correlations of 0.974 and 0.865 they showed greater interindividual differences than the dentists.

The intrarater reliability was excellent for all study participants and over the 23 measurement points: The dentists tended to be slightly better than the MTRAs with $\alpha$ between 0.994 and 0.964 and between 0.981 and 0.918 respectively.

The calculation of validity (agreement between intraoral measured values and laboratory values) showed very strong positive correlations for all 23 measuring points for both dentists (Pearson correlation $\mathrm{r}=0.967$ ) and MTRAs $(r=0.922)$ (Table 5). Evaluation of these correlations [16] showed that the dentists had a better agreement with the laboratory values than the MTRAs $(p=0.002)$.

Differences between the groups were found for the deviations of the mean values of the measurements from the laboratory values. Among the dentists, a very small, nonsignificant deviation of -0.003 was found. For the MTRAs, the deviation was -0.016 . It differed both from the laboratory value $(p=0.011 ; \mathrm{T}=-2.60 ; \mathrm{df}=91)$ and from the dentists' results $(p=0.032 ; \mathrm{T}=2.18 ; \mathrm{df}=91)$.

To determine the influence of the two ligated arch wires, Cronbach's $\alpha$ and the Pearson correlation were calculated separately for the quadrants with and without arcs (Tables 4 and 5).

The separate determination of the validity showed that the difference between dentists and MTRAs in the overall calculation was caused by the ligated arches, because this difference was not found in the individual examination of the 3rd quadrant (without arch wires). Overall, however, the agreement values and correlations consistently remained in the excellent or strongly positive range. Fig. 5 shows the scattering caused by the arch wires.

\section{Discussion}

Until now, radiologists and orthodontists did not have a valid and on-site available database for deciding whether intraoral metal objects can remain in situ prior to a head and neck MRI. We proposed a direct measurement of the relative magnetic permeability with an appropriate device (Ferromaster) and investigated its applicability under intraoral conditions. With its upper measuring range limit of 
Table 4 Agreement of measured values between the examiners and between repeated examinations with joint and separate calculation of the quadrants

Tab. 4 Übereinstimmung der Messwerte zwischen den Untersuchern und zwischen wiederholten Untersuchungen bei summarischer und bei separater Berechnung der Quadranten

\begin{tabular}{|c|c|c|c|c|}
\hline \multirow[t]{2}{*}{ Cronbach's $\alpha$} & \multirow{2}{*}{$\begin{array}{l}\text { Summarized calculation } \\
21 \text { brackets, } 2 \text { arch wires }(n=23)\end{array}$} & \multicolumn{3}{|c|}{ Separate calculation of the 1 st, 2 nd and 3 rd quadrant } \\
\hline & & With steel wire $(n=7)$ & With Ti-Mo wire $(n=7)$ & Without wire $(n=7)$ \\
\hline \multicolumn{5}{|l|}{ Dentists } \\
\hline Interrater reliability & 0.992 & 0.987 & 0.990 & 0.997 \\
\hline Intrarater reliability & $\begin{array}{l}0.994-0.964 \\
\text { best/worst rater }\end{array}$ & $\begin{array}{l}0.983 \\
\text { summarized }\end{array}$ & $\begin{array}{l}0.954 \\
\text { summarized }\end{array}$ & $\begin{array}{l}0.986 \\
\text { summarized }\end{array}$ \\
\hline \multicolumn{5}{|l|}{$M T R A$} \\
\hline Interrater reliability & 0.979 & 0.984 & 0.956 & 0.995 \\
\hline Intrarater reliability & $\begin{array}{l}0.981-0.918 \\
\text { best/worst rater }\end{array}$ & $\begin{array}{l}0.939 \\
\text { summarized }\end{array}$ & $\begin{array}{l}0.945 \\
\text { summarized }\end{array}$ & $\begin{array}{l}0.976 \\
\text { summarized }\end{array}$ \\
\hline
\end{tabular}

MTRA medical-technical radiology assistants

Table 5 Agreement of the clinically and in vitro determined permeability with joint and separate calculation of the quadrants with and without arch wires

Tab. 5 Übereinstimmung der klinisch und in vitro ermittelten Permeabilität mit gemeinsamer und separater Berechnung der Quadranten mit und ohne Drahtbögen

\begin{tabular}{llll}
\hline $\begin{array}{l}\text { Pearson } \\
\text { correla- } \\
\text { tion }\end{array}$ & $\begin{array}{l}\text { All measur- } \\
\text { ing points } \\
(n=23)\end{array}$ & $\begin{array}{l}\text { 3rd quadrant } \\
\text { without wires } \\
(n=7)\end{array}$ & $\begin{array}{l}\text { 1st and 2nd quad- } \\
\text { rant with metal } \\
\text { wires }(n=14)\end{array}$ \\
\hline Dentists & $0.967^{*}$ & 0.984 & $0.966^{* *}$ \\
MTRA & $0.922^{*}$ & 0.960 & $0.917^{* *}$ \\
\hline
\end{tabular}

MTRA medical-technical radiology assistants

$* p=0.002, * * p=0.009$

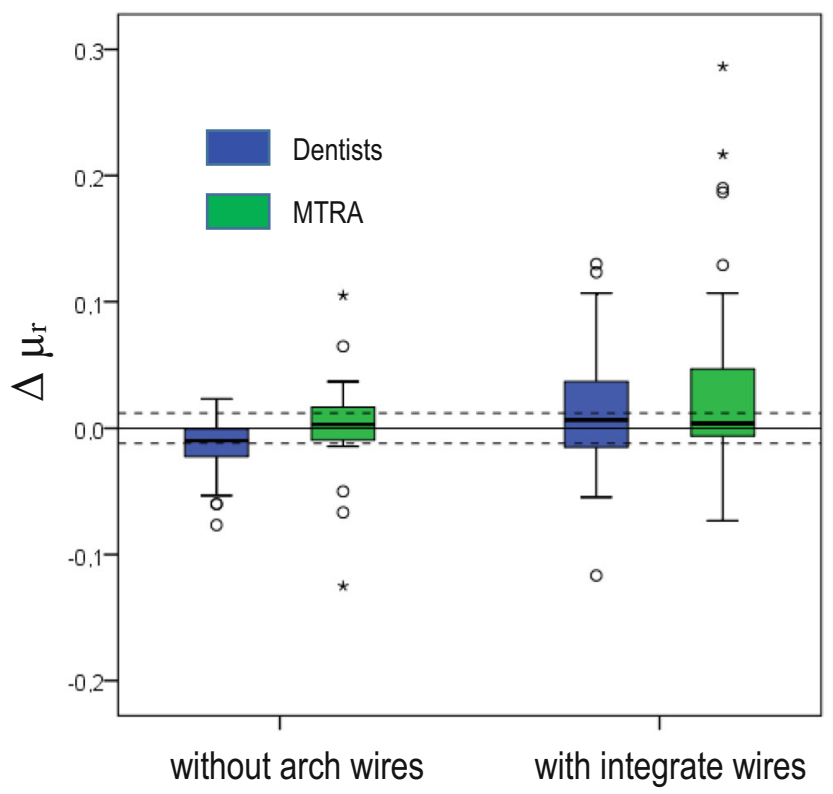

Fig. 5 Average deviations $\left(\Delta \mu_{\mathrm{r}}\right)$ of the clinical permeability measurements from the laboratory values on brackets with and without arch wires. The dashed line shows the measurement deviation of \pm 0.012

Abb. 5 Die gemittelten Abweichungen $\left(\Delta \mu_{\mathrm{r}}\right)$ der klinischen Permeabilitätsmessungen auf Brackets mit und ohne Drahtbogen von den entsprechenden Laborwerten. Die gestrichelte Linie zeigt die Messabweichung des Gerätes von $\pm 0,012$
1.999 it is suitable for all potential metals. They can be divided into two groups based on their magnetizability:

- Alloys based on titanium, cobalt and nickel as well as stable austenitic stainless steels with $\mu_{\mathrm{r}}<1.01$

- Metastable austenitic or martensitic steels with $\mu_{\mathrm{r}}$ up to 1.8 .

Keepers for monomagnetic attachments are an exception as they are specifically manufactured from highly ferromagnetic alloys such as PdCo $\left(\mu_{\mathrm{r}} \approx 240\right)$. In these, the maximum value of the measuring range of 1.999 is displayed. We tested the accuracy of the measurement under the manufacturer's application restrictions for undersized, nonplanar and remanently magnetizable objects. Due to its conformity to EN 60404-15 and ASTM 342, a high precision of the measuring device was to be expected. However, we were able to show that the precision is excellent even on clinically used small, nonplanar objects.

The trueness as a second accuracy criterion was decreased on our undersized objects. Nevertheless, we were able to show that the true (target) $\mu_{\mathrm{r}}$ values of strongly undersized objects can be calculated with sufficient accuracy from the nonexact (actual) values by experimentally created correction formulas. The exemplary determined correction factors apply to the respective volume. However, the determined curves demonstrate that this is a proportionally systematic deviation which only occurs when leaving the starting point of the curves. This results in the following statement which is essential for a screening: independent of the object size and taking into account the measuring deviation, a measurement result of the Ferromaster of $\mu_{\mathrm{r}} \leq 1.002$ is always correct.

The third manufacturer's restriction to only use the measuring device on remanent objects after they have been demagnetized is intended to prevent the permanent magnet in the probe from being altered by external fields and thus rendering the device unusable. In fact, products 9-14 (Table 2) were already magnetized by exposure to the weak field of 
the probe, but these remanent fields did not further amplify after exposure to the main field of the MRI, which is about 40 times stronger. The first exposure of these soft magnetic steel types which are typically used for medical purposes already produced saturation magnetization, which can no longer be increased. The remanence of medical steels that occurs at magnetic saturation is far too low to affect the measuring probe. Thus, our study shows the irrelevance of this use restriction of the manufacturer for planned clinical application. The only exception are intraoral primary magnets of the duo-magnet attachments which are used for anchoring implant-supported dentures or epitheses. Their field can be up to $140 \mathrm{mT}$ and would render the small magnets of the Ferromaster probe useless. Thus, anamnesis prior to MRI should involve asking for intraoral fixed mini magnets when the patient is wearing a removable prosthesis.

This is because MR exposure of such magnets leads to maximal artifacts and may further, depending on their position to $\mathrm{B}_{0}$, cause insufficiency of the attachments. When in doubt, a simple field sensor in the form of a small bar magnet, freely rotatable in all axes, can be applied to determine whether the object is a magnet or just a ferromagnetic product.

In the present study, we were able to show that possible artifacts can be better predicted with a direct permeability measurement than by knowing the present alloy. This is demonstrated by some of the products listed in Table 2: product No. 8 consists of two steels (DIN 1.4404 and 1.4301 ) with a metastable austenitic structure. Accordingly, $\mu_{\mathrm{r}}$ was 1.00 . The magnetizability declared in the steel standard and the measured magnetizability agree. This is due to the production process "metal injection moulding" (MIM), where the original microstructure is retained in the final product. Products No. 9, 10 and 11 are made of the same steel grades, but our measurements showed $\mu_{\mathrm{r}}$ values up to 1.48. This massive discrepancy is due to local martensite formation caused by cold deformation or hardening during the production process, which makes them magnetizable [7, 15].

As an example, this is shown in two patients wearing similar orthodontic appliances in the posterior region during MR examination (Figs. 6 and 7): The metal brackets were made of metastable austenites of the same grade; however, the way the brackets were manufactured was very different. In patient A (Fig. 6), brackets were cold-formed products that triggered major artifacts. In patient B (Fig. 7), brackets had been manufactured using the MIM process and were not visible in the imaging.

On the other hand, a $\mu_{\mathrm{r}}$ reduction is also possible without changing the official specification of a steel. For example, $\mu_{\mathrm{r}}$ of grade 1.4301 can be reduced from 1.075 to 1.011 by solution annealing [10]. Products with this reduced value are considered nonferromagnetic and would not produce any

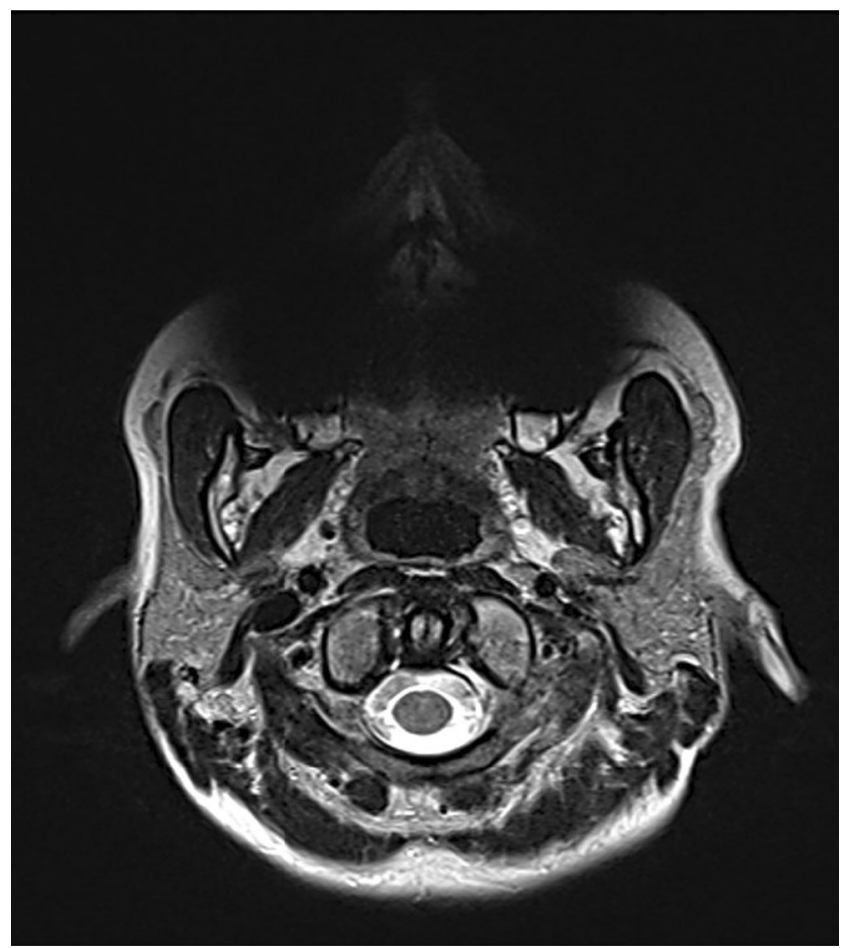

Fig. 6 Patient A: MRI image (1.5T): transversal section at the level of the dens axis, T2-weighted TSE sequence (TR: 5.700/TE: 112). Ceramic brackets on the anterior teeth, metal brackets on premolars and molars, made of the metastable austenitic steel grade 1.4301 (DentalVertrieb $2000 \mathrm{GmbH}$, Alsbach-Hähnlein, Germany). Measured permeability $\mu_{\mathrm{r}}=1.472$. Limited assessability due to susceptibility artifacts Abb. 6 Patient A: MRT-Bild (1,5T): transversaler Schnitt auf Höhe des Dens axis, T2-gewichtete TSE-Sequenz (TR: 5.700/TE: 112). Keramikbrackets an den Frontzähnen, die Metallbrackets an den Prämolaren und Molaren sind aus dem metastabile austenitischen Stahl 1.4301 (Dental-Vertrieb $2000 \mathrm{GmbH}$, Alsbach-Hähnlein/Deutschland) hergestellt. Gemessene Permeabilität $\mu_{\mathrm{r}}=1,472$. Eingeschränkte Beurteilbarkeit aufgrund von Suszeptibilitätsartefakten

relevant artifacts in the MRI. Since this state is not subject to declaration, it can only be found by direct measurement.

In a survey among radiologists in Germany, $40 \%$ of the participants were open to the idea of a clinical intraoral permeability measurement [14]. In the present study we have shown for the first time that this is feasible with excellent reliability and validity and without professional dental experience. The slightly poorer MTRA results could be further improved with feedback training (comparison with laboratory values). Because of the blinding effect, this was omitted in this study. The outliers observed in Fig. 5 were most likely due to positioning errors during the measurement on the ligated arch wires.

In order to prevent an unintended learning effect among the study participants and to exploit the full measuring range of the Ferromaster, we placed different brackets and tubes made of different alloys and from different manufacturers on the appliance of the test subject. In clinical reality, measurement should be even simpler, as the compilation of 


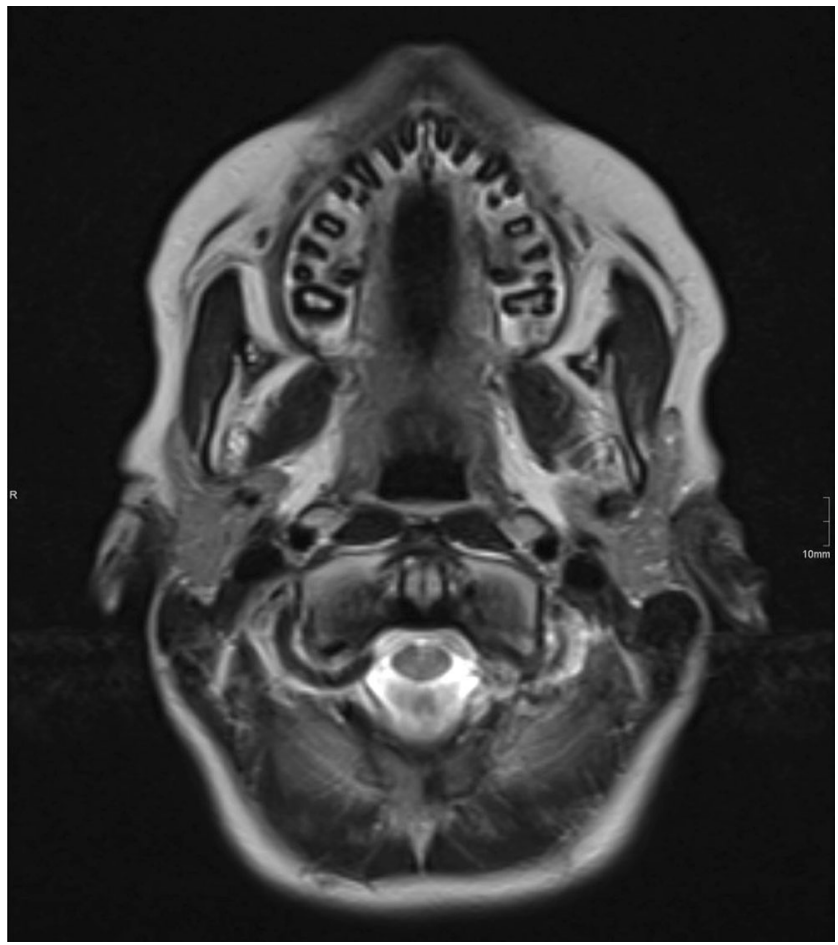

Fig. 7 Patient B: MRI image (1.5T): transversal section at the level of the dens axis, T2-weighted TSE sequence (TR: 5.400, TE: 125). Ceramic brackets on the anterior teeth and premolars, metal brackets on the molars, made of the metastable austenitic steel grades 1.4301, 1.4404 and 1.4501 (Dentaurum GmbH \& Co. KG). Measured permeability $\mu_{\mathrm{r}}=1.001$. Artifact-free imaging. The alveoli of the maxillary teeth fitted with brackets are also displayed without interference. (Image source: Dr. Gabriele Hahn, Dresden University Hospital)

Abb. 7 Patient B: MRT-Bild (1,5T): transversaler Schnitt auf Höhe des Dens axis, T2 gewichtete TSE-Sequenz (TR: 5.400, TE: 125). Keramikbrackets an den Frontzähnen und Prämolaren, Metallbrackets an den Molaren, hergestellt aus den metastabilen austenitischen Stahlsorten 1.4301, 1.4404 und 1.4501 (Dentaurum GmbH \& Co. KG). Gemessene Permeabilität $\mu_{\mathrm{r}}=1,001$. Artefaktfreie Bildgebung. Auch die Alveolen der mit Brackets versehenen Oberkieferzähne sind störungsfrei dargestellt. (Bildquelle: Dr. Gabriele Hahn, Universitätsklinikum Dresden)

"real" orthodontic appliances is less diverse than the one used in this study.

The presented method can be used for all directly accessible and not instantly removable metal objects: For example, on activation rods of maxillofacial surgical distractors, on splints and bimaxillary fixations and, if applicable, on fixed intraoral or extraoral piercings.

The measurement meets the criteria for a physical screening, which means that it can filter out from a set of elements those that exhibit the required property. The detection of a $\mu_{\mathrm{r}}$ value $\leq 1.002$ reliably indicates the absence of magnetizability, regardless of the object size. We showed that within this range, the device was able to measure with the same high precision and trueness even on very small objects and without a correction factor. Furthermore, the quality criteria of medical screening tests can be applied, since sensitivity and specificity were $100 \%$ in this value range.

As $\mu_{\mathrm{r}}$ values increase and depending on the distance between the objects and the region of interest, radiologists must then decide whether removal of the material is essential or whether less artifact-prone sequences or sequence modifications can allow the objects to remain intraorally. However, relevant artifact-reducing modifications are not yet available for all diagnostically required sequences.

Thus, future diagnostic studies should investigate the correlation between $\mu_{\mathrm{r}}$ values $\geq$ to 1.002 and the artifact size that occur for a wide range of MR sequences.

\section{Conclusions}

Even the few available manufacturer's specifications on the magnetizability of dental and oral surgical metal products often convey a false impression. This property, however, is the crucial material-related predictor for unwanted interactions in MRI. The method for permeability measurement tested in this study using a commercial device slightly modified for this purpose can be utilized as a chair-side screening for artifact formation. Nonmagnetizable objects can be reliably distinguished from magnetizable objects. The precision of the measurement is high on all potential objects, and trueness is high for objects with $\mu_{\mathrm{r}} \leq 1.002$. For objects with higher $\mu_{\mathrm{r}}$ values, correction factors can be calculated.

Remanence induced by exposure to strong external magnetic fields does not affect these measurements. After simple instruction dentists and medical staff without clinicalintraoral experience can clinically apply it with excellent reliability and validity under "waiting room conditions". The additional use of orthodontic arch wires increases the dispersion of the measured values while presenting the same high validity.

This method can replace the frustrating material research of dental products. It finally offers the radiologist a valid and rapidly available decision-making aid as to whether fixed metallic materials can remain completely in situ prior to MRI. This could avoid unnecessary material removal and concomitant expense and discomfort.

Also, contrary to the opinion expressed in many publications, a selective evaluation of individual metallic components is possible for the first time, since a reliable distinction can be made between nonpermeable and highly permeable parts.

A Germany-wide survey has shown that radiologists consult the treating orthodontist when in doubt about intraoral appliances [14]. We hope that this study can also promote interdisciplinary understanding between the two specialties. This is also important considering that MRI may become 
a diagnostic tool for orthodontics in the future, for example for cephalometric analysis [12].

Acknowledgements The authors thank Dr. Gabriele Hahn (Institute of Diagnostic and Interventional Radiology, University Hospital Carl Gustav Carus in Dresden) for kindly providing Fig. 7 and Andreas Thomas (Institute of Radiology, Charité-Universitätsmedizin Berlin) for Fig. 6.

Funding Open Access funding enabled and organized by Projekt DEAL.

\section{Declarations}

Conflict of interest F.H. Blankenstein, U. Kielburg, L. Melerowitz and M. E. D. Stelmaszczyk have no conflicts of interest to declare that are relevant to the content of this article.

Ethical standards The human study described here was conducted with the consent of the competent ethics committee (vote EA2/139/17 of 12th September 2017) and in accordance with the Declaration of Helsinki in its current version. Consent to participate: In accordance with the requirements of the Charite Ethics Committee, the eight investigators (4 dentists and 4 MTRA) and the subject were informed about the study and their written informed consent was obtained. Consent for publication: Written informed consent was obtained.

Open Access This article is licensed under a Creative Commons Attribution 4.0 International License, which permits use, sharing, adaptation, distribution and reproduction in any medium or format, as long as you give appropriate credit to the original author(s) and the source, provide a link to the Creative Commons licence, and indicate if changes were made. The images or other third party material in this article are included in the article's Creative Commons licence, unless indicated otherwise in a credit line to the material. If material is not included in the article's Creative Commons licence and your intended use is not permitted by statutory regulation or exceeds the permitted use, you will need to obtain permission directly from the copyright holder. To view a copy of this licence, visit http://creativecommons.org/licenses/by/4. $0 /$.

\section{References}

1. Bauer P (2019) Implant clarification. Management in clinical practice. Radiologe 59:894-897

2. Beau A, Bossard D, Gebeile-Chauty S (2015) Magnetic resonance imaging artefacts and fixed orthodontic attachments. Eur J Orthod $37: 105-110$

3. Blankenstein F, Truong BT, Thomas A, Thieme N, Zachriat C (2015) Zur Vorhersagbarkeit von Suszeptibilitätsartefakten durch metallische orthodontische Apparaturen in der Magnetresonanztomographie. J Orofac Orthop 76:14-29

4. Blankenstein FH, Asbach P, Beuer F, Glienke J, Mayer S, Zachriat C (2017) Magnetic permeability as a predictor of the artefact size caused by orthodontic appliances at $1.5 \mathrm{~T}$ magnetic resonance imaging. Clin Oral Investig 21:281-289

5. Cassetta M, Pranno N, Stasolla A et al (2017) The effects of a common stainless-steel orthodontic bracket on the diagnostic quality of cranial and cervical 3T-MR images: a prospective, case-control study. Dentomaxillofac Radiol 46(6):20170051

6. Darren G, Mallery P (2002) SPSS for Windows step by step: a simple guide and reference, 11.0 update. Allyn \& Bacon, Boston, p 231
7. Deutsche Edelstahlwerke (2016) Werkstoffdatenblatt X2CrNiMo17-12-2, 1.4404. https://www.dew-stahl.com/fileadmin/ files/dew-stahl.com/documents/Publikationen/

Werkstoffdatenblaetter/RSH/1.4404_de.pdf. Accessed 21 Mar 2019

8. Elison JM, Leggitt VL, Thomson M et al (2008) Influence of common orthodontic appliances on the diagnostic quality of cranial magnetic resonance images. Am J Orthod Dentofacial Orthop 134:563-572

9. Evidat Statistical Apps + Consulting (2019) Korrelationskoeffizienten interpretieren. https://www.evidat.com/correlation-coefficient. Accessed 13 June 2019

10. Fofanov D, Heubner U (2013) Merkblatt 827, Magnetische Eigenschaften nichtrostender Stähle. https://www.edelstahl-rostfrei.de/ downloads/iser/MB_827.pdf. Accessed 4 July 2019

11. Görgülü S, Ayyildiz S, Kamburoglu K et al (2014) Effect of orthodontic brackets and different wires on radiofrequency heating and magnetic field interactions during 3-T MRI. Dentomaxillofac Radiol 43(2): 20130356

12. Juerchott A, Saleem MA, Hilgenfeld T et al (2018) 3D cephalometric analysis using magnetic resonance imaging: validation of accuracy and reproducibility. Sci Rep 8(1):13029

13. Kemper J, Klocke A, Adam G et al (2005) Kieferorthopädische Brackets in der Hochfeld Magnetresonanz-Tomographie: Experimentelle Beurteilung magnetischer Anziehungs- und Rotationskräfte bei 3 Tesla. Fortschr Röntgenstr 177:1691-1698

14. Kielburg U, Blankenstein FH (2019) Metallobjekte der Kopf-HalsRegion im MRT - Eine Umfrage unter Radiologen. Radiologe 59:906-911

15. Knigge J (2015) Lokale Martensitbildung in metastabilen austenitischen Stählen durch Verfahren der Massivumformung. Technik und Wissen GmbH, Hannover, pp 3-23

16. Lenhard A (2017) Psychometrica, Signifikanztests bei Korrelationen. https://www.psychometrica.de/korrelation.html\#dependent. Accessed 13 June 2019

17. Linetskiy I, Starcuková J, Hubálková H et al (2019) Evaluation of magnetic resonance imaging issues of titanium and stainless steel brackets. Sci Asia 45:145-153

18. Okano Y, Yamashiro M, Kaneda T, Kasai K (2003) Magnetic resonance imaging diagnosis of the temporomandibular joint in patients with orthodontic appliances. Oral Surg Oral Med Oral Pathol Oral Radiol Endod 95:255-263

19. Pimentel-Gomes F (2009) Curso de estatística experimental. ESALQ, Piracicaba, $\mathrm{p} 477$

20. Regier M, Kemper J, Kaul MG et al (2009) Radiofrequency-induced heating near fixed orthodontic appliances in high field MRI systems at 3.0 Tesla. J Orofac Orthop 70:485-494

21. Sadowsky PL, Bernreuter W, Lakshminarayanan AV, Kenney P (1988) Orthodontic appliances and magnetic resonance imaging of the brain and temporomandibular joint. Angle Orthod 58:9-20

22. Sfondrini MF, Preda L, Calliada F et al (2019) Magnetic resonance imaging and its effects on metallic brackets and wires: Does it alter the temperature and bonding efficacy of orthodontic devices? Materials 12:3971

23. Stefan Mayer Instruments (2013) Ferromaster Permeabilitätsmessgerät, Bedienungsanleitung, pp 2-9

24. Regulation (EU) $2017 / 745$ of the European Parliament and of the Council of 5 April 2017on medical devices, amending Directive 2001/83/EC, Regulation (EC) No 178/2002 and Regulation (EC) No 1223/2009 and repealing Council Directives 90/385/EEC and 93/42/EEC. Amended by Regulation (EU) 2020/561 of the European Parliament and of the Council of 23 April 2020

25. Wylezinska M, Pinkstone M, Hay N et al (2015) Impact of orthodontic appliances on the quality of craniofacial anatomical magnetic resonance imaging and real-time speech imaging. Eur J Orthod 37:610-617 
F. H. Blankenstein et al.

26. Yassi K, Ziane F, Bardinet E et al (2007) Evaluation of the risk of overheating and displacement of orthodontic devices in magnetic resonance imaging. J Radiol 88:263-268

Publisher's Note Springer Nature remains neutral with regard to jurisdictional claims in published maps and institutional affiliations. 